Arteterapia. Papeles de arteterapia y educación para inclusión social ISSN-e 1988-8309

\title{
El arte que cura: Aplicación de técnicas vs la violencia. Experiencias en Baja California, México ${ }^{1}$
}

\author{
Teresa Fernández de Juan²
}

Recibido: 26 de marzo de 2017 / Aceptado: 13 de julio de 2017

Resumen. Se presenta un compendio de experiencias relacionadas con el estudio, investigación y aplicación, durante varios años, de diversas técnicas relacionadas con el arte y la cultura, en poblaciones tanto de niños como de jóvenes y para prevenir aspectos relacionados con la violencia en Baja California, México. Entre los procedimientos abordados se encuentra la cinematerapia, utilizada tanto para advertir sobre el maltrato hacia el medio ambiente, como para combatir la violencia escolar (bullying) y la del noviazgo. Así como otras modalidades aplicadas a jóvenes con fines preventivos y educativos. Palabras clave: Arteterapia, prevención de violencia, México, cinematerapia.

\section{[en] Art that heals: implementation of technical vs. violence. Experiences in Baja California, Mexico}

\begin{abstract}
It presents some experiences of the study, research and application for several years of various techniques related to art and culture in populations of both children and young people cases, to prevent violence in Baja California, Mexico-related aspects. Were selected as samples, the application of the cinematherapy to save the violence against the environment, the fight against school violence (bullying) and dating, as well as other techniques applied in young people for precentive and educational purposes.
\end{abstract}

Keywords: Art therapy; prevention of violence; Mexico; cinema therapy

Sumario. 1. Introducción. 2. La cinematerapia. 3. La cinematerapia vs la violencia doméstica en niños. 4. Películas. 5. Cinematerapia infantil para promover una relación sana con la naturaleza y en la lucha contra el bullying. 6. Comentarios sobre los Resultados. 7. Técnicas para la prevención y detección de violencia en las relaciones de noviazgo. 8. Resultados de una propuesta de intervención. 9. Técnicas utilizadas. 10. Resultados. 11. Conclusiones.

Cómo citar: Fernández de Juan, T. (2017). El arte que cura: Aplicación de técnicas vs la violencia. Experiencias en Baja California, México, en Arteterapia. Papeles de arteterapia y educación para inclusión social 12, 95-107.

1 A lo largo de todo el trabajo se manejará el término en masculino como es costumbre en el lenguaje, o sea, no como una exclusión al género femenino, sino para ayudar a la sintaxis y la lectura.

2 Doctora en psicología y especialista en género, violencia, musicoterapia y arteterapia. Profesora-investigadora titular del Departamento de Estudios Culturales de El Colegio de la Frontera Norte. Carretera Escénica TijuanaEnsenada km 18.5 San Antonio del Mar, 22560, Tijuana, Baja California, México. Correos:<teresaf@colef. $\mathrm{mx}>\mathrm{y}<$ teruquilinda3@yahoo.com.mx $>$ 


\section{Introducción}

Las artes tienen la facultad de mejorar la calidad de vida de las personas y comunidades. Durante décadas han devenido en un poderoso instrumento para estimular el desarrollo, tanto intelectual como emotivo, de quienes encuentran en la expresión artística un medio de comprender el mundo y de conectarse con los otros.

A su vez, numerosos estudios develan que entre los jóvenes, la violencia ha alcanzado un nivel tan alarmante que ha llegado a convertirse en su principal causa de muerte. En este sentido, hace poco encontramos en la primera plana del afamado periódico semanal Zeta (2016): "Eneyda Noriega, estudiante de 22 años de la Facultad de Medicina de la Universidad Autónoma de Baja California (UABC) en Tijuana, fue encontrada asesinada alrededor de las 7:00 de la tarde del sábado 30 de abril". Su cadáver fue encontrado asfixiado con una bolsa plástica y en el hogar de la novia de su ex pareja, perteneciente a la misma Facultad y con quien se suponía mantenía aún buenas relaciones. Y, desgraciadamente, este no es un caso aislado. Se va tornando cada vez más frecuente entre las parejas jóvenes incluso de nivel universitario, que son las más conocidas por los medios.

Por otro lado, durante el año pasado murieron al menos cinco mil menores, esta vez por causas relacionadas con el bullying. A escala nacional, en México existe un registro de 4201 varones y 989 mujeres que perdieron la vida en 2012 por acoso escolar. Estadísticas de la Secretaría de Salud estatal revelan que las edades más propensas son de entre 10 y 14 años; en 2010 se registraron 10 suicidios y en 2011 la cifra se elevó a 20 casos (Robles, 2013). Y no sólo sucede en el ámbito escolar; la violencia doméstica afecta a los niños física y psíquicamente, aun cuando sólo sean testigos de la misma en el hogar. En general, México tiene más de 39 millones de menores de edad, de los cuales 6 de cada 10 han padecido violencia en su casa o escuela, de acuerdo con el Fondo de las Naciones Unidas para la Infancia (UNICEF, por sus siglas en inglés). Quienes crecen en estas circunstancias son estigmatizados $\mathrm{y}$, si sobreviven, lo hacen en un ambiente hostil y violento que moldea su conducta y personalidad.

Como ya expresábamos, estudios recientes (Fernández y González, 2015; Fernández, Martínez, Unzueta y Rojas, 2016), muestran que la violencia entre los jóvenes ha ido en ascenso, al punto de que desconocen que muchas de sus manifestaciones lo son, por lo que pasa inadvertida por parte de la víctima y el victimario hasta que se recrudece. También fue notorio el hecho de que muchos de estos grupos habían tomado previamente clases de género, sin que esto influyera absolutamente en sus conductas destructivas o autodestructivas y permisivas. Símbolo indiscutible de que estos talleres no sólo deben acrecentarse, sino sobre todo cambiar la forma de su impartición, tornándolos realmente vivenciales para que realcen su importancia y visibilidad sobre la base de sus propios sentires y prácticas. La experiencia de la autora en estas cuestiones la ha llevado al convencimiento de que la prevención y tratamiento de los distintos tipos de violencia cuenta, entre sus instrumentos más valiosos, con las técnicas de arteterapia, que coadyuvan a su instrucción, concientización y cambio de forma motivadora, como corresponde a una buena educación y a su proceso posterior de cura.

En este trabajo se muestra un resumen de algunas experiencias de investigación-acción llevadas a cabo en México con este fin, en poblaciones diversas y con herramientas disímiles, siempre en la lucha y la prevención del maltrato. De cada 
una de ellas aparece la fuente bibliográfica de la que podría extraerse toda la información recabada, en lo que aquí se exponen los pasos fundamentales de los que constan para su posible réplica en otros contextos. En cada caso fueron escogidas varias modalidades fundamentales, mismas que permiten apreciar la accesibilidad que brinda el arte para el logro de cambios ante los problemas que la violencia acarrea (léase ansiedad, identidad, autoestima y otros). Al respecto cabe señalar que las técnicas de expresión artística encuentran cada vez mayor posibilidad de uso como herramientas terapéuticas de gran eficacia para el autocrecimiento.

\section{La cinematerapia}

En un primer momento, el trabajo hará énfasis en el uso de esta técnica, definida como la intervención terapéutica que permite al paciente evaluar visualmente la interacción de los caracteres de un filme, con otras personas, en sus ambientes y sus aspectos personales, envolviéndolo en un nivel emocional, físico y cognitivo, que le facilitan el avance terapéutico. Remonta sus orígenes a la "biblioterapia" utilizada desde 1916, aunque no fue sino hasta 1990 cuando se acuñó este término. Para su uso se cuenta con la apropiada selección de las películas a utilizar, tomando en cuenta la idiosincrasia del grupo o individuo a tratar, con la pretensión de que no toda su vida sea representada sino solamente el aspecto específico del que se está tratando. También es importante que la asignación de la tarea sea explícita. Como han expresado antes estudiosos en la materia, la discusión realizada en la sesión posterior se enfatiza en el personaje, manteniéndola a distancia de la (o las) persona(s) a tratar, lo cual facilita que amplíen su percepción de la situación. Como actividad personalizada se plantea que se recurra a ellas como metáforas terapéuticas, de forma que un cliente en tratamiento psicológico pueda, sin excesivas dificultades, identificar cuál es su problema, se motive a comunicar mejor sus emociones y logre así resolverlo con recursos propios. El debate final persigue el objetivo de lograr una actividad analítica por parte de los participantes, desarrollar sus facultades de expresión, mantenerse motivados y aumentar su conocimiento en algunos aspectos claves de su vida.

\section{La cinematerapia vs la violencia doméstica en niños}

A partir de la premisa de que lo idóneo en el tratamiento del maltrato infantil es un trabajo simultáneo con los padres (en la medida de lo posible), y que los grupos de apoyo y educacionales son indispensables, se aprovechó la experiencia de Módulos de Apoyo del Centro de Protección Social de la Mujer del Sistema Nacional para el Desarrollo Integral de la Familia (DIF) de Tijuana (Baja California, México), adonde asisten conjuntamente los hijos con sus madres, para implementar con ellos y por separado un programa de módulos de cinematerapia, como técnica complementaria a la atención musicoterapéutica que recibían las madres, a su vez violentadas. Para esta aplicación piloto (Fernández, 2006), se seleccionaron diferentes películas según los objetivos propuestos, tales como: favorecer la capacidad de análisis para facilitar el aprendizaje, las relaciones interpersonales y la toma de decisiones; reforzarla afectividad, motivar la sociabilidad (basada en la igualdad, aceptación diversidad 
y el respeto) y propiciar una identificación apropiada de su rol social. Es de destacar que en este programa, específicamente, se consideró un reto encontrar películas adecuadas, debido a la variabilidad etaria del grupo de estudio. Las cintas debían mostrar, de forma amena y a la vez comprensible para todos, diferentes modelos de comportamiento, permitiéndoles entenderse a sí mismos y observar otras formas de manejar la vida, de enfrentarse a los problemas cotidianos (en este caso de violencia o relacionados con ésta) y de relacionarse; interpretándolas, asimilándolas y apropiándose de aquello que les favorezca.

En relación a la metodología, el grupo estuvo compuesto por ocho niñas y tres niños (once infantes en total) desde el segundo grado de primaria hasta el segundo de secundaria, con edades entre los 7 y los 14 años de edad y un estrato socioeconómico bajo-medio. Como parte del procedimiento, asistieron una vez a la semana durante nueve sesiones. Una vez terminada la proyección, se realizaba una exploración de lo observado. Al finalizar el programa, plasmaron de manera grupal las experiencias, emociones y enseñanzas obtenidas a lo largo del mismo a través de la técnica del collage (en la cual, por medio de recortes, expresaron su experiencia durante la asistencia al grupo).

Existen diversas situaciones infantiles que son intervenidas con la cinematerapia. Entre ellas están las relaciones personales ("Babe, el puerquito valiente"), relaciones familiares ("Mary Poppins"), duelo ("E.T".), logro e individualidad ("Antz"), las etapas del desarrollo ("Goofy"), la amistad y la superación de obstáculos ("The Secret Garden). Sin embargo, es de destacar que, a pesar de haber sido reconocido el efecto del cine tanto en los niños como en los adolescentes, no encontramos antecedentes de su aplicación ante la prevención y tratamiento en el maltrato hacia los menores (cfr Fernández, 2012).

\section{Películas}

1ra sesión: Su objetivo fue resaltar la importancia de la amistad y la valentía para atrevernos a hacer cosas diferentes, cuidarnos y vivir con alegría. Como podemos aprender de las cualidades de los animales, a los cuales son muy cercanos los niños, se escogió "Spirit: El corcel indomable". La temática central de esta película fue la autoestima, la seguridad en sí mismos y la expresión de sus sentimientos, que involucraban miedos y problemas en sus relaciones interpersonales.

2da sesión: Tuvo como objetivo fomentar el desarrollo de nuevas formas de relación e interacción social, la igualdad, la aceptación y el respeto hacia los demás. Se escoge para ello el filme: "Dinosaurios", el cual resalta la esperanza de un futuro mejor, la perseverancia y el apoyo que otras personas requieren de nosotros. También cómo nos enriquece el trabajo en equipo y las alternativas sanas para solucionar conflictos. La lección que aprendieron, con su discusión, es que "para convivir, hay que tener paciencia ante las cosas que les causan dificultades a otros", y a "no dejarse vencer por los obstáculos que se les presenten".

3ra sesión: El objetivo es que el niño aumente sus recursos para desarrollarse dentro del medio en que vive. La película proyectada se titula "Babe, el puerquito valiente", en la cual se aborda el tema de la socialización sana y la integración familiar, aunado a los valores de respeto y solidaridad; de gran valor para la convivencia. 
4ta sesión: Para promover la autoestima y el auto cuidado cuando se enfrenten a situaciones difíciles. Película: "Buscando a Nemo", considerando las relaciones (amistades) que influyen positiva y negativamente, así como el valor de la perseverancia.
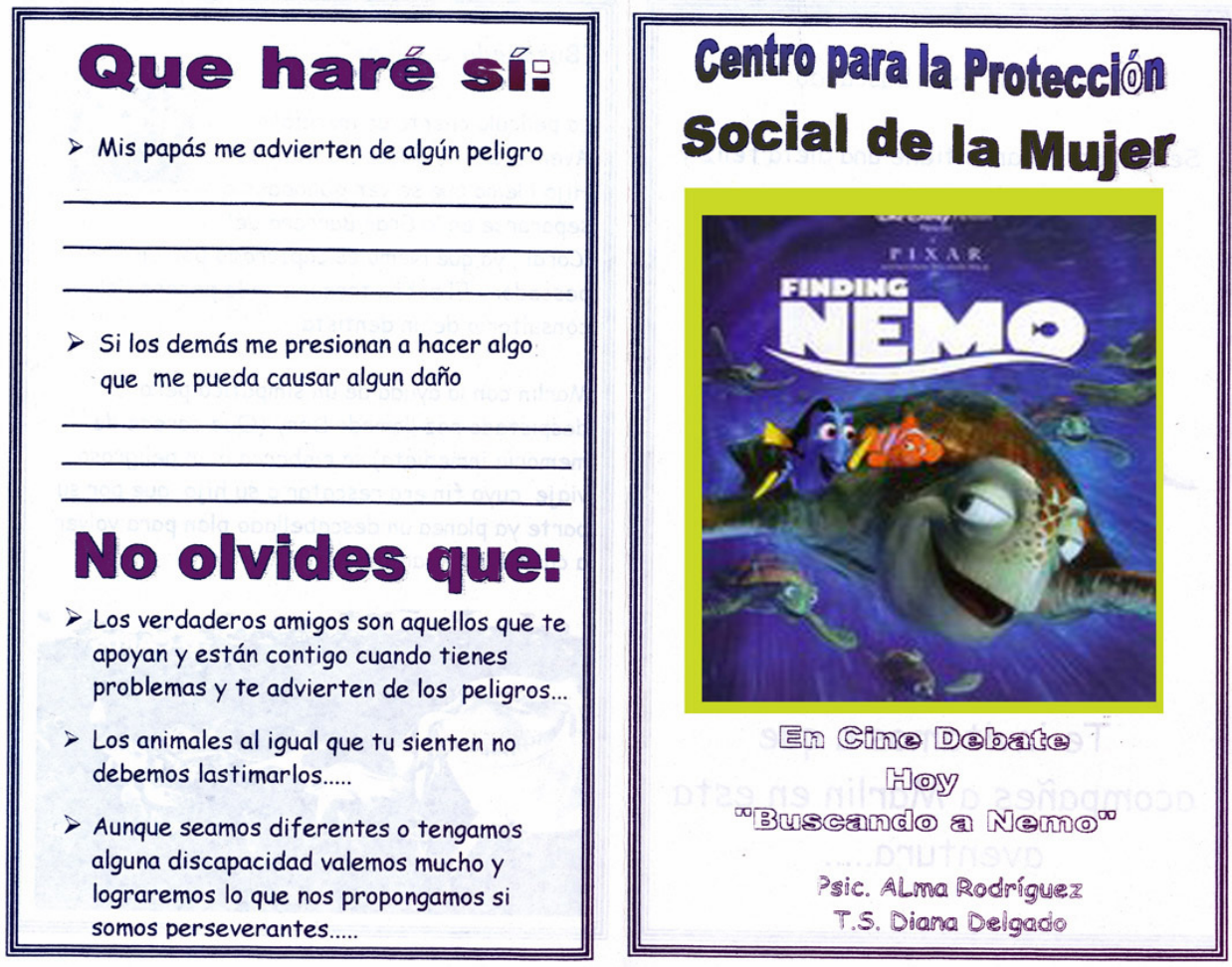

Foto 1. Material entregado a los niños luego de la proyección de Nemo para su discusión.

5ta sesión: Objetivo: Impulsar la autoestima y el auto concepto proyectando un modelo de trabajo en equipo como fomentador de amistad, amor, honestidad, responsabilidad, respeto y libertad. La película a proyectar en esta sesión fue "Shrek", que nos habla del rechazo de la gente a un ogro y a su soledad y a la vez enseña a no juzgar a los demás; algunas de sus frases posteriores fueron: "No se debe dejarse llevar por las apariencias" y "hay que valorar a los amigos".

6ta sesión: Se resalta la importancia del trabajo en equipo, ya que fomenta valores como son la responsabilidad, la solidaridad, la unión, el amor y la tolerancia. La película seleccionada fue "La era de hielo" debido a que manifiesta elementos de integración familiar, la colaboración entre pares y el respeto, a través de las acciones en los animales, que son sus protagónicos.

7ma sesión: El objetivo es promover la igualdad entre hombres y mujeres, así como el valor de la toma de decisiones. La película a proyectar fue "Mulán”, la cual permitió enfatizar en el tema de la autoestima, las decisiones, el amor en la familia y a la comunidad, así como el reconocimiento de los estereotipos de género. 
8va sesión: Con el objetivo de promover el autoconocimiento y trabajar los sentimientos de culpa en lo que respecta a la relación de los padres, se proyecta "Mi encuentro conmigo", que narra la historia de un hombre exitoso que ha pasado toda su vida intentando olvidar quién fue de niño.

9na sesión: En esta sesión los participantes elaboraron un collage, donde plasmaron su experiencia en el grupo. Se formaron 3 equipos, donde a través de recortes de revistas resaltaron la importancia del trabajo, de quererse y respetarse a sí mismos, del auto cuidado y de perseverar en sus metas. Reconocieron que aprendieron a analizar las lecciones de todo lo proyectado y que deseaban ponerlo en práctica en sus vidas. Por último, se les hizo entrega de un cofre pequeño que contenía todas las frases que elaboraron durante el análisis de las películas, animándolos a que, cuando pasaran por una situación difícil, acudieran a él y sacaran las frases para traerlas a su memoria y reconfortarse.

Resultados: Es de señalar, como consta en Fernández (2006), que los niños pertenecientes a esta experiencia piloto mostraron cambios perceptibles al finalizar los módulos fijados, elevaron su autoestima y adquirieron mayor seguridad en sí mismos dentro de un espacio y con una terapia que así lo permitía. De manera que, a través de una actividad lúdica, pudieron exteriorizar muchas de sus preocupaciones y problemas sin sentirse amenazados, ya que lograron verse reflejados en muchos de los personajes y situaciones de las películas seleccionadas, adquiriendo así nuevos valores de forma indirecta. Entre ellos se contaban elementos de los que se sentían responsables producto de la violencia en el hogar y la esperanza de un cambio dentro de un fatalismo conceptual, con la implicación de un futuro forjado en nuevos valores.

\section{Cinematerapia infantil para promover una relación sana con la naturaleza y en la lucha contra el bullying}

En un segundo proyecto (Fernández, 2013), destinado esta vez a lograr una mayor integración social en una comunidad con problemas de violencia de diverso tipo entre ellos violencia hacia la naturaleza, violencia escolar y casos de bullying (Fernández y Silvan, 2014) — , la aplicación de la cinematerapia tuvo otros fines. Fueron proyectados, con un fin concientizador y educativo:

a) El documental "S.O.S. El llamado", que buscaba ofrecer a los participantes un panorama más amplio de lo que sucede en el planeta en la actualidad, relacionado con la problemática ambiental (que incluye aspectos como los cambios negativos acaecidos por las acciones indiscriminadas del ser humano, con vistas a inculcar en el infante el respeto al medio ambiente natural).

Basados en experiencias investigativas internacionales previas y en los resultados prácticos de organizaciones enfocadas a la educación ambiental del área de estudio, fueron seleccionados los abordajes que coadyuvaran a una cohesión efectiva con el entorno. En aras de su mayor efectividad, este comprendió la intervención escolar sin descuidar las características culturales de la región y su análisis se realizó a través de dinámicas que consideraran los beneficios que aportaba al bienestar humano la conexión con el medio. Por lo tanto, en esta proyección sus objetivos consistían 
en: facilitar la toma de conciencia de los beneficios personales y comunitarios de conectarse con la naturaleza; estimular el desarrollo de capacidades creativas, y canalizarlo hacia la búsqueda del auto-cuidado, la armonía interior y la comunicación saludable, en estrecha relación con la apreciación del entorno y su preservación.

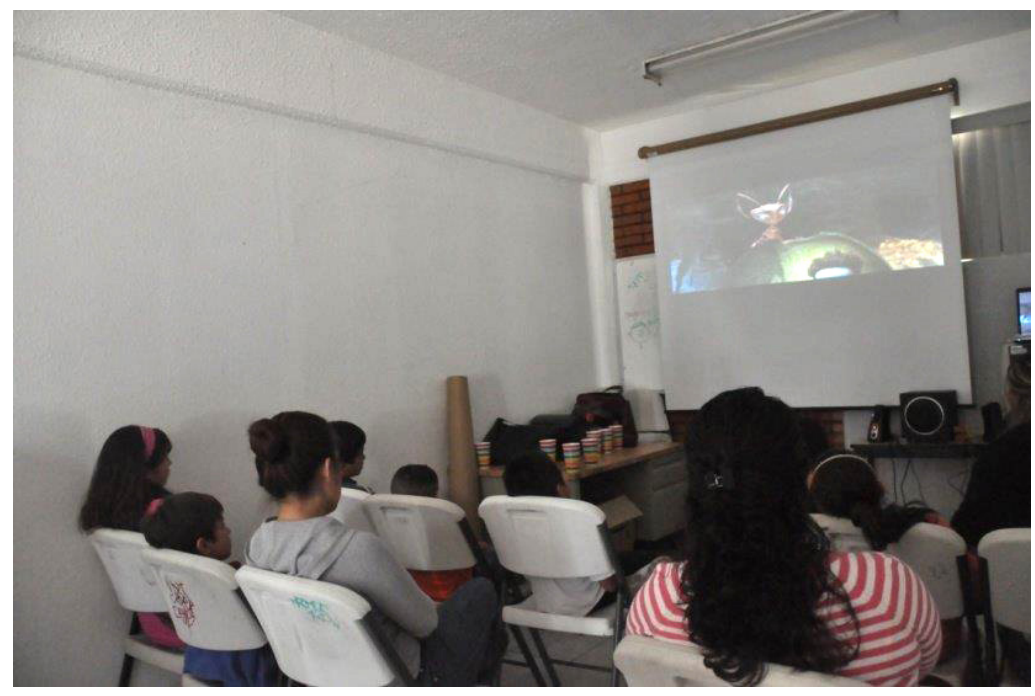

Foto 2. Actividad de proyección en cinematerapia

b) Por otra parte, para discutir y concientizar acerca de los aspectos relacionados con el acoso escolar o bullying, se proyectó y analizó posteriormente la película: "Antibully", partiendo de que los integrantes poseen una historia semejante a la de los niños participantes.

En cuanto a esta problemática, cabe señalar que cada vez es más común escuchar acerca de situaciones de violencia entre los niños debido al acoso escolar (bullying), en la modalidad de golpes, discriminación y amenazas en las escuelas, tanto a nivel internacional como en México en particular. Instancias internacionales como la Comisión Económica para América Latina (CEPAL) en el 2011 señalan que más del 40 $\%$ de los estudiantes mexicanos en sexto grado declararon que en sus escuelas fueron víctimas de robo, el $25.3 \%$ de insultos o amenazas, el $16.7 \%$ golpes y casi el $45 \%$ dijo haber sufrido algún episodio de violencia (Román y Murillo, 2011).

El bullying es una palabra proveniente del vocablo holandés que significa acoso. Se trata de un anglicismo que se podría traducir como "matonismo" (bully significa matón y to bully, intimidar con gritos y amenazas y maltratar a los débiles). Para ser acoso escolar se necesita ser una conducta violenta y reiterativa. El primero que empleó este término en el sentido de persecución o acorralamiento escolar en sus investigaciones, fue el Dr. Dan Olweus en 1978, quien implantó en la década de los '70 en Suecia un estudio a largo plazo sobre el tema. Tiene varias modalidades, como son: el acoso entre alumnos, el de los alumnos a los maestros, el de los maestros hacia a los alumnos y el de padres de familia a alumnos o a maestros. En este trabajo sólo se abordó el bullying entre alumnos, entendiendo al término como: "la intimidación o el maltrato entre escolares, de forma repetida y mantenida en el tiempo, casi siempre 
lejos de la mirada de los adultos, con la intención de humillar y someter abusivamente a una víctima indefensa, a través de agresiones físicas, verbales, psicologías y/o sociales". (SSP 2012: 15)

Fueron tomados como referencia dos planteles de Baja California Norte, donde sus directivos presentaron quejas al respecto y solicitaron el apoyo de la Procuraduría de los Derechos Humanos. De hecho, se mostrará en este trabajo un estudio práctico realizado en una de ellas: CET del Mar No. 11.

Procedimiento: El taller se realizó en la escuela CET del Mar No. 11, ubicada en la colonia el Sauzal en el municipio de Ensenada, acudieron niños de entre 6 y 12 años. También se proyectaron otras películas, como:

c) "Buza Caperuza", con el objetivo de ayudar a reflexionar sobre la importancia de comunicarnos de manera clara, respetuosa y efectiva. Utilizada para asimilar conocimientos, racionalizar y reflexionar tanto a nivel cognitivo como emocional, pues permite relacionar la trama del filme con la vida cotidiana y, a partir de esa realidad, darle un sentido a la propia experiencia.

d) "Gnomeo y Julieta", para discutir y descubrirlas distintas alternativas de resolución. El mensaje de la película va destinado a vencer los prejuicios y no heredar la cadena de odios o venganza de los adultos.

\section{Comentarios sobre los resultados}

Como se aprecia detalladamente en: de Anda, M y Fernández (2013), al aplicar un test de retroalimentación al final de las sesiones, los niños ya identificaban nuevas formas de abordar sus conflictos sin ser necesariamente la evitación su única opción, e incluso indicaban que se podían "arreglar" con aquellos con quien se tiene problemas y volver a ser amigos. Un dato relevante es que gran parte del grupo mencionó ser víctima de algún tipo de acoso escolar. También es de especial reconocimiento que los infantes, al mejorar su manera de comunicarse, ser más asertivos y trabajar en su propia estima, lograron exponer el tema ante sus propios familiares, e incluso algunos llegaron más lejos, llevándolo a sus aulas de estudio.

\section{Técnicas para la prevención y la detección de la violencia en las relaciones de noviazgo. Resultados de una propuesta de intervención}

Este último trabajo (González y Fernández, 2015) describe la importancia de abordar con mayor profundidad el tema de la violencia en las relaciones de pareja entre los jóvenes, de una manera tanto educativa como paliativa. A esta problemática, relativamente reciente en la investigación científica, se le prestó atención por primera vez a mediados del siglo XX. Se identificó como una preocupación social a partir del estudio realizado por Kanin en 1957, quien encontró que muchas estudiantes eran víctimas de amenazas o de relaciones sexuales forzadas durante el noviazgo. En el año 2007, México desarrolló una Encuesta Nacional de Violencia en las Relaciones de Noviazgo (ENVINOV) entre el 73\% de los mexicanos que poseían de 15a 24 años. La misma indicó que un $75.8 \%$ había sido víctima de violencia psicológica, 
un $16.5 \%$ había vivido al menos una experiencia de ataque sexual y un $15.5 \%$ de violencia física (Instituto Mexicano de la Juventud, 2007). Esta encuesta precisó, además, que este tipo de maltrato suele pasar desapercibido tanto para las instituciones como entre los propios jóvenes. Al respecto, Velázquez (2011:41) encontró que "el 25\% de las mujeres asesinadas por su pareja son novias entre los 14 y 25 años, que creyeron en el amor romántico y no velaron lo suficiente por su seguridad". Esta invisibilidad ha derivado en una falta de apoyo tanto institucional como familiar para los que se ven involucrados en estas situaciones con sus parejas, por lo que primero, no las reconocen, y luego, no saben cómo enfrentarlas.

Pero a pesar de su alta incidencia, existen pocos estudios en el país en general y en Baja California en particular. El que haya llegado a convertirse en algo invisible debido a su naturalización es doblemente alarmante, ya que, si partimos de que la juventud mexicana representa cerca de la quinta parte de la población del país, de no ser esta situación velozmente intervenida, se proyectará cada vez más en vida adulta de las parejas. Dada su frecuencia creciente y la gravedad de sus consecuencias (físicas, emocionales y sociales), es indiscutible la necesidad de desarrollar cada vez más programas de prevención e intervención en adolescentes, que incluyen la urgencia de incluir a todos los niveles una adecuada educación sexual. También resulta fundamental sensibilizar a la juventud para lograr un cambio en las conductas, actitudes y normas sociales que reproducen las prácticas y formas de violencia en las relaciones entre hombres y mujeres.

En cuanto al territorio de estudio seleccionado (Baja California), se explica por ser ésta una de las entidades de México actualmente considerada como de mayor índice de violencia en general y de violencia doméstica en particular, donde además se ha alcanzado mayor desarrollo económico y sociodemográfico, lo que se manifiesta en una más amplia incorporación de las mujeres al sistema de enseñanza y a la actividad productiva, así como a la sexualidad sin fines reproductivos y fuera del matrimonio (González, 2007). Por lo anteriormente apuntado, el objetivo general del trabajo que a continuación se resume fue el de desarrollar una nueva propuesta teórico-práctica de intervención, de corta duración, con un fin preventivo y paliativo, que pudiera además servir para su re-aplicación en otros planteles. Con la ayuda de las técnicas de arteterapia se enfatizó en el concepto de violencia en el noviazgo, sus consecuencias, el reconocimiento de los tipos en los que esta puede presentarse, las características del ciclo de la violencia y la atadura emocional que encubría. También se abordó el tema del género y de la equidad, para desmitificar prácticas, nociones y actividades que continúan reproduciendo este problema.

Muestra: El grupo de estudio comprendió a un total de 22 estudiantes seleccionados previamente por la escuela preparatoria del Centro de Estudios Tecnológicos del Mar No. 11 (CETMAR) en el Sauzal, Baja California. Las edades oscilaron entre los 14 a los 21 años, con un promedio de 17 años y un nivel socioeconómico de bajo a medio. Todos se encontraban cursando la educación media superior en esta institución. En cuanto al sexo, 14 fueron del sexo femenino y 8 del masculino.

Procedimiento: El taller se llevó a cabo a lo largo de 4 encuentros matutinos, los días sábado, con una duración total de 10 horas y en un salón previamente acordado de la propia escuela. En cada sesión se exponían los objetivos y se desarrollaban los tópicos escogidos, a través de diferentes dinámicas grupales; esto para propiciar su distensión y posterior catarsis de sentimientos, lo que aseguraría un aprendizaje significativo y vivencial sobre el problema a tratar. Se acompañaba de la información 
teórica indispensable, de la cual además se regalaban materiales y pruebas de autoevaluación para llevar a la casa o compartir con otros miembros de la comunidad.

\section{Técnicas utilizadas}

El Twister del violentómetro

- Objetivo: Introducir a los participantes al tema detectando, identificando y reconociendo los tipos y el grado de violencia en una relación de noviazgo a nivel personal, familiar y social.

- Material: Manta tamaño grande del "Violentómetro".

- Desarrollo: Los participantes se sitúan en un área donde se encuentra extendida la manta del violentómetro para "jugar" de manera similar al Twister. La actividad implicó que situaran en la(s) acción(es) de violencia que correspondiera en los grupos señalados (primero su comunidad, luego los vecinos, después la familia, etc.) según sus propias vivencias. En caso de abarcar más de una acción, podían ayudarse de cualquier parte del cuerpo para incluirlas al mismo tiempo. Al finalizar el taller, les fue donado a cada participante una reproducción tamaño marcador, con la finalidad de que pudieran revisarlo y apoyarse de él en distintas situaciones. Pero antes, se analiza y discute el tema en general, con preguntas como ¿Qué acciones de violencia en relaciones de pareja hemos presenciado o hemos sabido de su existencia en la sociedad (desconocidos)? ¿Qué acciones de violencia en relaciones de pareja hemos presenciado o hemos sabido de su existencia en nuestro entorno (conocidos, amigos y vecinos.)?¿Qué acciones de violencia hemos padecido en nuestras relaciones de noviazgo? ¿Qué acciones de violencia hemos ejercido en nuestras relaciones de noviazgo? Al finalizar se indaga sobre sus sentimientos, emociones surgidas y cuestiones que quisieran compartir con el grupo.

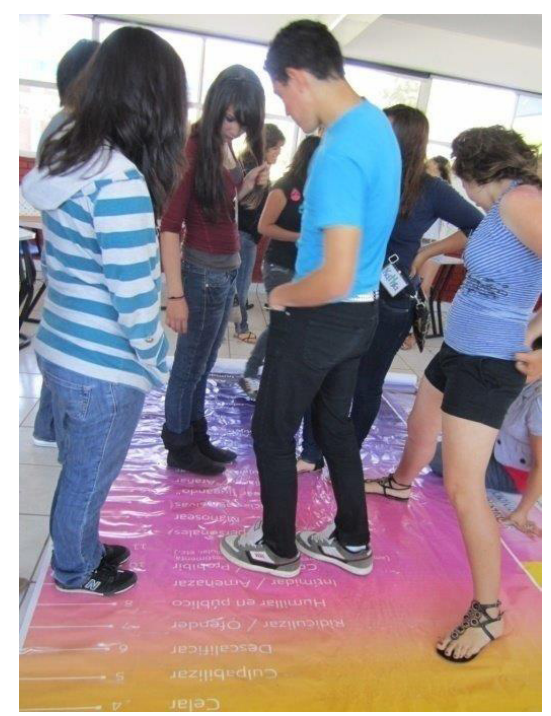

Foto 3. Jóvenes en la actividad del Violentómetro. 
Sociodramas: Aprendiendo a manejar los conflictos

- Objetivo: Reconocer situaciones de violencia en el noviazgo y estrategias para saber qué hacer en caso de presentase una situación de este tipo.

- Participantes: Equipos de 5-6 integrantes.

- Desarrollo: Reunidos en equipo, deben relatar voluntariamente situaciones de conflicto y de violencia que han observado en noviazgos de parejas jóvenes. Después se les asigna por equipos diferentes situaciones que podrían devenir en alguno de los tipos de maltrato más comunes a su edad (psicológico, físico y sexual), mismo que tuvieron que escenificar. A continuación, se procede a un debate sobre cada uno de los casos, y se contestan las preguntas que señale el arteterapeuta.
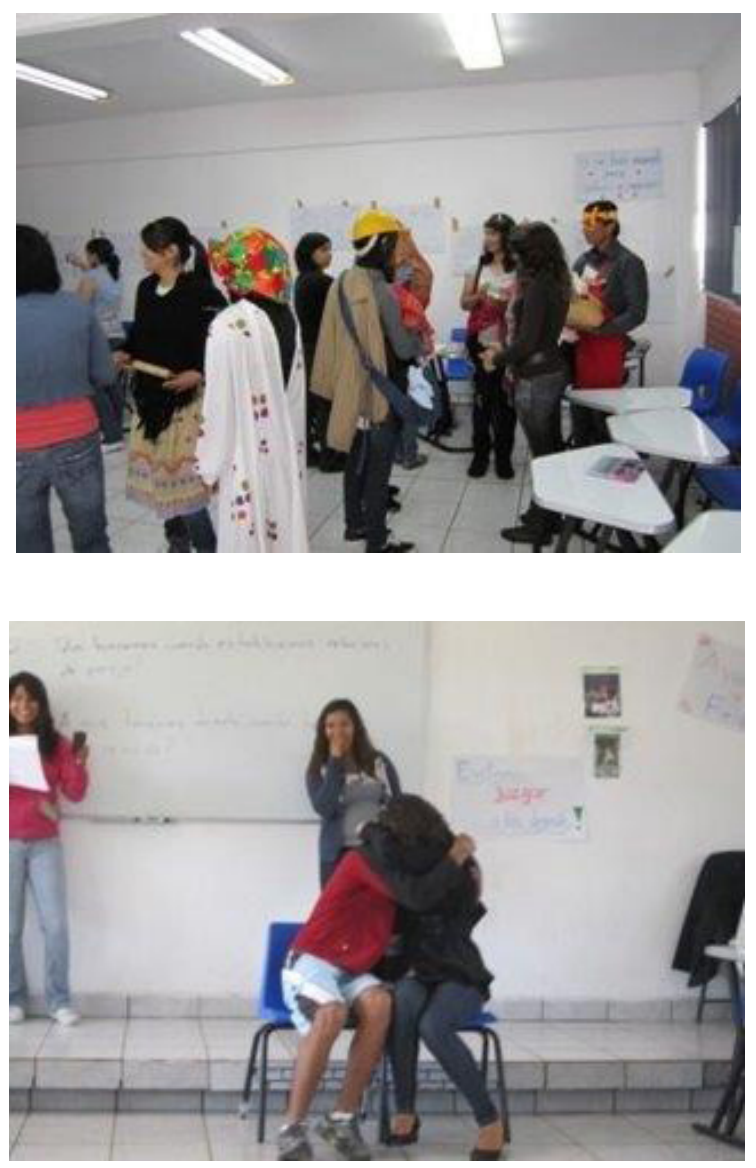

Fotos 4 y 5. Grupos de jóvenes en actividades de sociodrama.

Proyección y análisis de Videos sobre el tema

- Objetivo: Reflexión y sensibilización de los y las jóvenes con apoyo de videos y películas que muestren situaciones de violencia en el noviazgo; ofrecer información para que logren detectar, prevenir y saber cómo proceder cuando estas se presentan, y a la vez que mostrar una panorámica acerca de los dis- 
tintos tipos de violencia. (Material en video: "Presentación de la Encuesta Nacional de Violencia en las relaciones de Noviazgo 2007", "Violencia en el Noviazgo" (de la serie "Instantáneas" del Canal Once Tv de México) y el filme "Reviving Ophelia").

\section{Resultados}

Del "Sociodrama para aprender a manejar los conflictos", los participantes, aunque confesaron aspectos como el que "se siente incómodo, porque quieres estar con tus amigas y no quieres perder a tu novio", al final coincidieron en que lo más sano para poder tener una relación equilibrada era que "se requería tiempo a solas, con los amigos y con la familia". Que "el tener una pareja no requería aislarse del resto del mundo o permitir que tu novio(a) tratara de hacerlo". Y que "las parejas tenían que respetarse sus espacios como seres individuales". Ante los videos y película discutidos, tanto acerca las cifras de violencia en el país como ante un caso real y uno ficticio de violencia en el noviazgo, se vieron reflejados en varias de las situaciones. Comentaron que las pequeñas y casi invisibles agresiones, podrían terminar en algo mucho peor. Ante la dinámica de "El Twister del violentómetro", reconocieron haber sido testigos de violencia en el noviazgo con sus amigos de la escuela ante acciones como bromas hirientes, chantaje, celos, ignorar, culpabilizar, empujar o jalonear y "golpear jugando". La actividad concluyó acentuando la importancia de poder reconocer la violencia en cualquiera de sus expresiones para conseguir evitarla.

\section{Conclusiones}

El uso consciente y comprobado de técnicas de corte arteterapéutico, en este caso para prevenir y combatir la violencia, demostraron su capacidad de potenciar el auto-conocimiento y la transformación en grupo, ayudado por un ambiente que fomentó la expresión creativa y la comunicación. Todos pudieron expresarse a través de diferentes medios, utilizando un lenguaje de imágenes y símbolos como comunicación de contenidos y comparación de sensaciones y de vivencias emocionales. Por lo cual es evidente que esta metodología propicia la aparición de cambios favorables ante esta y otras problemáticas análogas, que aquejan a tantos niños y jóvenes de manera internacional.

\section{Bibliografía}

Fernández, T. \& Silvan, L. (2014). "El arte de interactuar con la naturaleza: Módulo experimental 'Armonía y medioambiente". En Arteterapia: Papeles de Arteterapia y Educación Artística para la Inclusión Social, vol. 9, pp. 87-98.

Fernández, T. (2013). "Taller de Integración Social y Autoestima. Estructura y resultados generales". En Plan de Acción para la innovación y competitividad de los valles vitivinícolas de Baja California, en http://seminariovallesvitivinicolas.blogspot.mx/2013/01/ view-reporte-final-taller-autoestima-on.html 
Fernández, T. \& González, A. (2015). "Relaciones de noviazgo libres de violencia entre jóvenes. Una propuesta de intervención”. En Revista Internacional PEI, vol. 9, s/p.

Fernández, T., Martínez, A., Unzueta, C. \& Rojas, E. (2016). "Violencia hacia los varones entre parejas jóvenes de universidades de Tijuana". En Enseñanza e Investigación en Psicología, vol. 21, núm. 3, pp. 255-263.

Fernández, T \& De Anda, M. (2013). "Bullying: Trabajo en escolares con una perspectiva dinámica desde la cultura de la paz y los derechos humanos". En La construcción de identidades agresoras: el acoso escolar en México (pp.187-208), México, CONACULTA.

Fernández, T. (2012). El Poder Terapéutico Detrás Del Arte: Experiencias Con Técnicas De Arteterapia Y Musicoterapia en Poblaciones que Padecen Violencia Doméstica. España, Editorial Académica Española.

Fernández, T. (2006). “Niños violentados: El cine-debate como opción terapéutica”. En Enseñanza e Investigación en Psicología, vol. 11, núm. 2, pp. 1-16.

González, H. (2007). "Cambios previsibles en los niveles de fecundidad de las adolescentes mexicanas: el caso de la frontera norte". En Frontera Norte, vol. 18, núm. 36, S.p.

Instituto Mexicano De La Juventud (2007). Encuesta Nacional sobre Violencia en el Noviazgo. Septiembre, 2011, de Imjuve Sitio web: http://www.inegi.org.mx/est/contenidos/ proyectos/encuestas/hogares/especiales/envin/default.aspx

Subsecretaría De Prevención Y Participación Ciudadana (SSP). (2012). Violencia Escolar: Apoyo Comunitario como Propuesta de Prevención. Febrero 21, 2017, de SSP Sitio web: http://www.ssp.gob.mx/portalWebApp/ShowBinary?nodeId=/BEA\%20Repository $/ 1214188 / /$ archivo

Robles, L. (Marzo 25, 2013). Reportan cinco mil muertes por bullying; Senado debate ley contra el acoso escolar. Febrero 28, 2017, de Excelsior Sitio web: http://www.excelsior. com.mx/nacional/2016/05/05/1090825

Román, M. y Murillo, J. (2011). “América Latina: violencia entre estudiantes y rendimiento escolar”. En Revista CEPAL, núm. 104, pp. 37-54.

Velázquez, G. (2011). La violencia durante el noviazgo en adolescentes. En Elementos, vol. 18, núm. 82, s/p., en http://www.elementos.buap.mx/num82/htm/39.htm.

Zeta. (Mayo 1, 2016). Buscan a sospechoso de asesinar a estudiante de Medicina en Tijuana. 